\title{
INCOME INEQUALITY IN NON-COMMUNICABLE DISEASES MORTALITY AMONG THE REGIONS OF THE SLOVAK REPUBLIC
}

\author{
Beáta Gavurová ${ }^{1}$, Viliam Kováč ${ }^{2}$, Michal Šoltés ${ }^{1}$, Sebastian Kot ${ }^{3,4}$, Jaroslav Majerník \\ ${ }^{1}$ Department of Banking and Investment, Faculty of Economics, Technical University of Košice, Košice, Slovak Republic \\ ${ }^{2}$ Department of Finance, Faculty of Economics, Technical University of Košice, Košice, Slovak Republic \\ ${ }^{3}$ Faculty of Management, Czestochowa University of Technology, Czestochowa, Poland \\ ${ }^{4}$ Faculty of Economic and Management Sciences, North-West University, Mafikeng, Republic of South Africa \\ ${ }^{5}$ Department of Medical Informatics, Faculty of Medicine, Pavol Jozef Šafárik University in Košice, Košice, Slovak Republic
}

\section{SUMMARY}

Aim: A great amount of non-communicable disease deaths poses a threat for all people and therefore represents the challenge for health policy makers, health providers and other health or social policy actors. The aim of this study is to analyse regional differences in non-communicable disease mortality in the Slovak Republic, and to quantify the relationship between mortality and economic indicators of the Slovak regions.

Methods: Standardised mortality rates adjusted for age, sex, region, and period were calculated applying direct standardisation methods with the European standard population covering the time span from 2005 to 2013. The impact of income indicators on standardised mortality rates was calculated using the panel regression models.

Results: The Bratislava region reaches the lowest values of standardised mortality rate for non-communicable diseases for both sexes. On the other side, the Nitra region has the highest standardised mortality rate for non-communicable diseases. Income quintile ratio has the highest effect on mortality, however, the expected positive impact is not confirmed. Gini coefficient at the 0.001 significance level and social benefits at the 0.01 significance level look like the most influencing variables on the standardised mortality rate. By addition of one percentage point of Gini coefficient, mortality rate increases by 148.19 units. When a share of population receiving social benefits increases by one percentage point, the standardised mortality rate will increase by 22.36 units.

Conclusions: Non-communicable disease mortality together with income inequalities among the regions of the Slovak Republic highlight the importance of economic impact on population health.

Key words: non-communicable diseases, income inequality, economic indicators, regional mortality

Address for correspondence: J. Majerník, Department of Medical Informatics, Faculty of Medicine, Pavol Jozef Šafárik University in Košice, Trieda SNP 1, 04011 Košice, Slovak Republic. E-mail: jaroslav.majernik@upjs.sk

https://doi.org/10.21101/cejph.a4958

\section{INTRODUCTION}

The mortality of a certain population is affected by the various types of demographic characteristics that can be divided on biosocial - sex, age, genetics, race - and sociocultural - education, income, occupation, marital status, religion (1). In addition, major risk factors, such as alcohol consumption, smoking, obesity, unhealthy life style, and physical inactivity are matters of the greatest importance in explaining mortality. A lot of studies reveal high differences between individual socioeconomic status in relation to the morbidity and mortality (2-4). Significant distinctions are seen in mortality for chronic diseases across, as well as within countries $(5,6)$. However, the non-communicable diseases represent the highest burden on population health. They are defined as the diseases which are not transmissible or caused by injury and are responsible for $68 \%$ of deaths worldwide (7). They include four main groups of chronic diseases: the cardiovascular diseases as I00-I99), the cancer as C00-C99, the chronic respiratory diseases as J30-J98), and the diabetes mellitus as E10-E14. Together, they account for $90 \%$ of all deaths in Slovak Republic (8).

Many studies prove that low-income countries have significantly higher mortality compared to the medium or high-income countries (9-12). Income inequality is tightly related to the poor health status, resulting in the more likely to mortality (13). Higher unequal income distribution in population leads to the higher mortality rates in the same group of people (14). Kennedy et al. (15) used two indicators expressing income inequality - the Gini coefficient and the Robin Hood index that were strongly correlated with mortality in the United States of America. On the contrary, Kaplan et al. (16) also proved the positive relationship between income inequality and mortality using the share of total income owned by the bottom $50 \%$ of the households. The association of six income inequality indicators with total mortality in the United States of America were examined in the study by Kawachi and Kennedy (17). They reported that it does not matter on the type of income indicators, while all were strongly correlated with 
mortality, even after transfers and tax adjustment. There are many studies that deal with socioeconomic disparities in mortality in the United States of America and the western Europe, but only a few papers deal with the Central and East European countries (18). According to Kunst (19), the Visegrad countries significantly lack the European Union.

Based on the previous studies, we decided to study a regional geographic distribution of mortality from the non-communicable diseases, and to estimate the power and significance of income inequality indicators as well as other economic variables in affecting the regional mortality from the non-communicable diseases in the Slovak Republic.

\section{MATERIALS AND METHODS}

The dataset comes from the two databases - obtained from the Statistical Office of the Slovak Republic and from the National Health Information Center of Slovak Republic, which provides primary source of national health statistics under the conditions of the contract.

\section{Data}

The data set explores the data from 2005 to 2013. As the elementary input data for the modelling process the mid-year state of all the population divided by the sex, the age groups and the individual regions in each explored year have been applied. Mortality rate is calculated as age-standardised to the revised European standard population by the age groups adopted by the Eurostat according to the last revision in 2012. It is expressed by standardised mortality rate, which is stated as number of total deaths per 100,000 inhabitants. The method of direct standardisation is applied to eliminate variances resulted from differences in age structure of the population across the regions and over time, ensuring the necessary conditions for comparing the regions of the Slovak Republic. The data concerning the involved economic indicators at the regional level are available only from 2005. Therefore, such a period to analyse is selected.

\section{Methodology}

The regression analysis is applied for the panel data set. The standardised mortality rate performs as an explained variable. The explanatory variables are listed in the executed regression analysis.

Altogether, in this case, the regression, which has been employed, has the following equation:

$$
S M R=\beta_{0}+\beta_{1} U R+\beta_{2} I+\beta_{3} P+\beta_{4} G C+\beta_{5} I Q R+\beta_{6} S B+\varepsilon
$$

where the involved variables mean:

- SMR - standardised mortality rate;

- $\beta_{0}$ - constant;

- UR - unemployment rate;

- $I$ - mean net disposable income of a household expressed in euro per month;

- $P$ - a share of population with income lower then at-risk-ofpoverty threshold to the whole population;
- GC-Gini coefficient;

- IQR - income quintile ratio;

- $S B$ - amount of all the social benefits of an individual expressed in euro per month;

$-\varepsilon$ - residual.

There are a few notes, which should be taken into consideration, to exactly specify the chosen income indicators. Unemployment rate means a ratio of a number of unemployed inhabitants to a number of the economically active inhabitants for the previous year. Mean equivalised net income per household represents a household disposable income divided by equivalent household size. Individual household members are assigned weights -1 for the first adult household member, then 0.5 per each additional adult member, 0.5 per each adolescent from 14 years of age and over, and 0.3 per each child younger than 14 years of age. At-risk-of-poverty threshold is set at $60 \%$ of national median equivalised disposable income of individual. It expresses the percentage of inhabitants with an equivalent disposable income below a set boundary. Gini coefficient is an indicator of monetary poverty, which shows the inequality of income distribution, and is defined as the relationship of cumulative shares of the population arranged according to the level of equivalised disposable income, to the cumulative share of the equivalised total disposable income received by them. It can gain values from 0 meaning absolute income equality to 1 signalling absolute income inequality. Income quintile ratio - S80/ S20 ratio - is a measure of income distribution inequality. It is calculated as a proportion of the total income of $20 \%$ of the richest people in society - located in the top quintile - relative to the total income of $20 \%$ of the poorest people - located in the lowest quintile. Social benefits include all the types of monetary social help aimed at poor, disabled, or otherwise handicapped people. This indicator expresses the whole amount of euro paid to the inhabitants that are allowed to obtain such a state financial aid.

In order to ensure that the examined model fulfils the requirements to evaluate it as the regression model, several test have been done. The significance level to determine acceptation or rejection of the zero hypothesis is set on a five-per-cent level. Therefore, we have tested the model for heteroscedasticity issue. To get an image about consistency of the input data, we have executed the tests of presence of data heteroscedasticity or homoscedasticity - the Breusch-Pagan test, the Goldfeld-Quandt test. We have applied the studentised version of the Breusch-Pagan test.

When analysing relation of mortality from various causes of death and economic indicators, we expect a positive linear relationship to the indicators expressing unemployment rate, poverty, Gini coefficient, income quintile ration and social benefits too. On the contrary, we expect a negative linear relationship with an equivalent disposable household income.

The whole analysis with all the computations is done in the $\mathrm{R}$ software environment.

\section{RESULTS AND DISCUSSION}

There are quite considerable regional differences in the Slovak Republic. As it is shown in the Table 1, also the particular economic indicators are very discerned.

Map visualisation gives a better look at the regional differences of standardised mortality rates in Slovak Republic. Firstly, 
Table 1. Descriptive statistics of the economic indicators describing the regions of the Slovak Republic, 2005-2013

\begin{tabular}{|c|c|c|c|c|c|c|c|c|}
\hline \multirow{2}{*}{ Indicator } & \multicolumn{8}{|c|}{ Region } \\
\hline & Bratislava & Trnava & Trenčín & Nitra & Žilina & B. Bystrica & Prešov & Košice \\
\hline \multicolumn{9}{|c|}{ Unemployment rate } \\
\hline Minimum & 2.0 & 4.3 & 4.5 & 7.1 & 5.6 & 14.1 & 12.1 & 13.0 \\
\hline Maximum & 6.2 & 9.4 & 10.9 & 14.1 & 12.8 & 20.8 & 20.7 & 19.6 \\
\hline Mean & 3.9 & 7.2 & 8.1 & 10.9 & 9.7 & 17.7 & 16.6 & 16.5 \\
\hline SD & 1.7 & 2.1 & 2.7 & 2.5 & 2.8 & 2.4 & 3.1 & 2.2 \\
\hline \multicolumn{9}{|c|}{ Mean equivalised net income per household } \\
\hline Minimum & 458.8 & 358.5 & 337.4 & 307.3 & 342.2 & 338.1 & 289.0 & 344.3 \\
\hline Maximum & 778.2 & 637.7 & 674.0 & 600.7 & 636.8 & 592.2 & 555.9 & 603.1 \\
\hline Mean & 653.5 & 518.2 & 512.9 & 478.6 & 516.3 & 481.2 & 444.4 & 487.4 \\
\hline SD & 101.4 & 101.1 & 113.0 & 101.3 & 105.7 & 93.3 & 91.8 & 90.1 \\
\hline \multicolumn{9}{|c|}{ At-risk-of-poverty } \\
\hline Minimum & 5.1 & 6.7 & 7.0 & 11.8 & 8.5 & 10.0 & 13.6 & 10.9 \\
\hline Maximum & 8.0 & 10.9 & 13.0 & 16.3 & 12.7 & 16.9 & 21.3 & 13.5 \\
\hline Mean & 6.8 & 8.7 & 9.4 & 14.0 & 10.6 & 14.0 & 17.8 & 12.4 \\
\hline SD & 0.9 & 1.5 & 1.7 & 1.8 & 1.4 & 2.1 & 2.6 & 0.9 \\
\hline \multicolumn{9}{|c|}{ Gini coefficient } \\
\hline Minimum & 25 & 21.4 & 19.5 & 22.8 & 23.1 & 22.9 & 21.7 & 21.4 \\
\hline Maximum & 39.6 & 25.4 & 30 & 27.8 & 25.6 & 29 & 26.7 & 25.7 \\
\hline Mean & 28.9 & 23.0 & 23.5 & 24.6 & 24.2 & 25.1 & 23.9 & 23.7 \\
\hline SD & 4.8 & 1.5 & 2.9 & 1.7 & 0.8 & 1.9 & 1.7 & 1.3 \\
\hline \multicolumn{9}{|c|}{ Income quintile ratio } \\
\hline Minimum & 3.7 & 3 & 2.7 & 3.2 & 3.3 & 3.2 & 3 & 3.1 \\
\hline Maximum & 6.6 & 3.6 & 4.3 & 4.2 & 3.7 & 4.6 & 4.4 & 3.8 \\
\hline Mean & 4.4 & 3.2 & 3.4 & 3.6 & 3.5 & 3.7 & 3.6 & 3.4 \\
\hline SD & 1.0 & 0.2 & 0.5 & 0.3 & 0.1 & 0.4 & 0.5 & 0.2 \\
\hline \multicolumn{9}{|c|}{ Social benefits } \\
\hline Minimum & 1.0 & 3.3 & 2.2 & 5.2 & 2.9 & 8.3 & 7.9 & 9.7 \\
\hline Maximum & 1.6 & 5.1 & 3.5 & 7.8 & 4.4 & 11.7 & 11.1 & 13.0 \\
\hline Mean & 1.2 & 3.9 & 2.8 & 6.2 & 3.6 & 10.6 & 10.1 & 11.6 \\
\hline SD & 0.2 & 0.5 & 0.3 & 0.7 & 0.4 & 1.0 & 1.0 & 1.0 \\
\hline
\end{tabular}

SD - standard deviation

general view is provided for the whole population. Consecutively, only for female sex and only for male sex map visualisation is provided. All the maps are assigned to the two time moments - to the beginning of the observed time span in 2005 and to the end of this time span in 2013. The mean values for the whole observed period are displayed in the third map always too.

The Bratislava region bears the most appropriate figures representing standardised mortality rate for non-communicable diseases generally. On the opposite side the Nitra region stands with the worst number. However, the Banská Bystrica region had the highest standardised mortality rate at the beginning of the explored period. The northern part of the Slovak Republic has got slightly worse its rate throughout the time span except from the Trenčín region as seen on Figure 1.

Development of standardised mortality rate for female sex is partially altered. Overall improvement during the whole observed time span is slightly better than in a case of male sex. However, the best position and the worst position for the particular regions are identical to the previous ones as seen on Figure 2.

The situation in a case of male sex is very similar to the one of the whole population. Development of the standardised mortality rate is analogous too. The Bratislava region holds the best position, whilst the worst one is assigned to the Nitra region as seen on Figure 3.

\section{Regression Analysis}

To model the standardised mortality rate, we have constructed the panel regression model applying a random approach. Firstly, we have employed the indicators stated in the methodology chapter with a constant value. After execution of this regression model, we have decided to leave a constant value in order to improve statistical significance of the model. Hence, its value in the below describing models is equal to 0 . In other words, we 


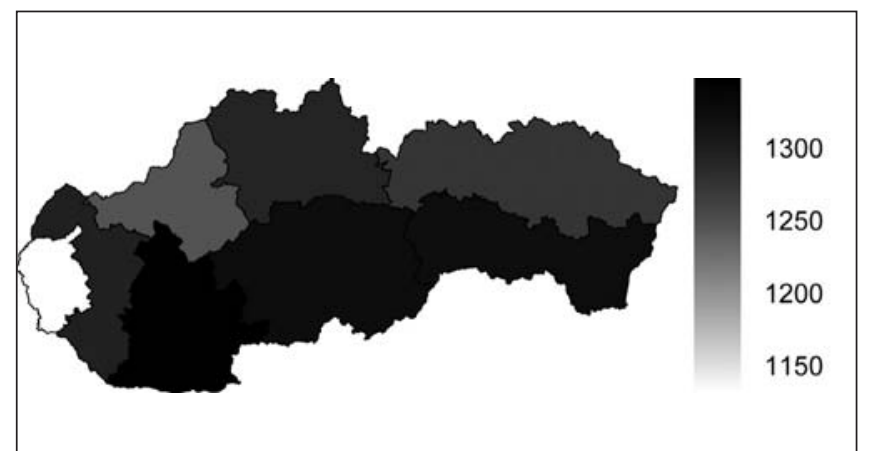

Fig. 1. The average standardised mortality rate of non-communicable diseases in the regions of the Slovak Republic in the period from 2005 to 2013.

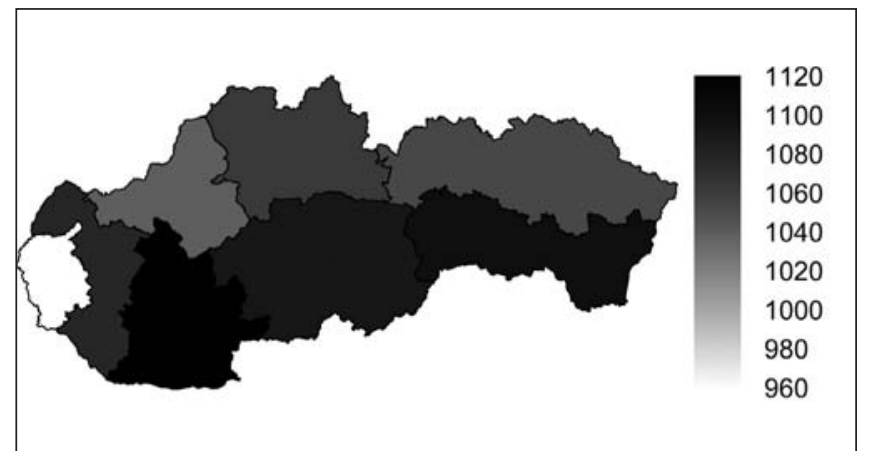

Fig. 2. The female average standardised mortality rate for noncommunicable diseases in the regions of the Slovak Republic in the period from 2005 to 2013.

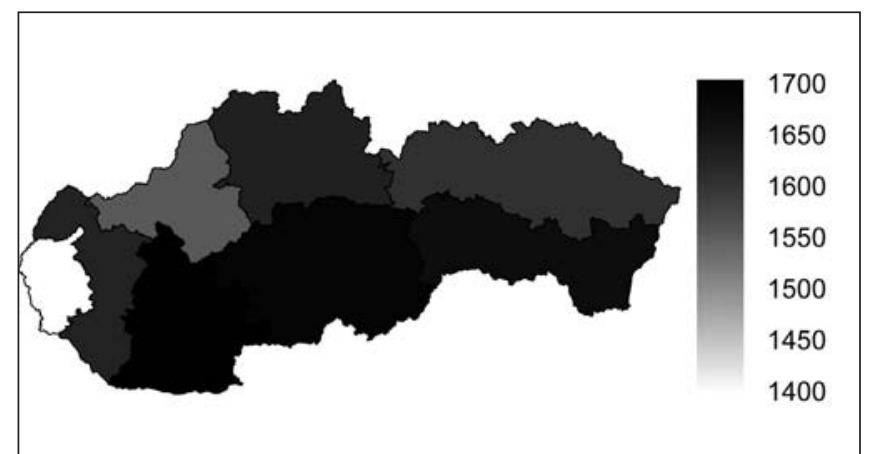

Fig.3. The male average standardised mortality rate of noncommunicable diseases in the regions of the Slovak Republic in the period from 2005 to 2013. do not count on it. The model series concerning the data coming from the whole population - from the both sexes - involves the two regression models as seen in Table 2.

The fundamental regression formula for the first model series M1 is conveyed as follows:

$$
\begin{aligned}
& S M R=-4.75 U R-0.26 I+15.46 P+150.69 G C-712.61 I Q R \\
& -21.29 S B
\end{aligned}
$$

The five of all the six comprised variables are statistically significant. The only one not fulfilling the statistical significance requirement is the UR variable. Differentiation lies in the significance levels. The GC variable performs as the best one. The IQR can be considered as the statistically very significant too. The $\mathrm{P}$ and SB variables fulfil a five-per-cent significance level. Finally, the I variable jumps very slightly over a five-per-cent significance level. Because the UR variable is not statistically significant, it is going to be discarded from the model.

The second appropriate model M2 has the following formula:

$$
S M R=-0.33 I+11.69 P+148.19 G C-694.75 I Q R+22.36 S B
$$

After an exclusion of the UR variable, the I, IQR and SB variables have improved their statistical significance, although it is irrelevant change by the IQR variable, because its p-value is very low nevertheless. The $\mathrm{G}$ variable has remained at the same minimum level. Only the $\mathrm{P}$ variable has got worse $\mathrm{p}$-value, but it is only very marginally above a standard five-per-cent significance level. Summarily, all the variables are statistically significant on the various levels.

The most substantial variable of the regression is the IQR variable, followed by the GC variable. These two variables affect the standardised mortality rate in order of hundreds. The SB and P variables influence the explaining variable in order of tens. The least influencing variable is the I variable, which has impact in order of tenths. Whilst the IQR and I variables have a negative effect, the other variables - GC, SB and P- have a positive effect, what construes a situation, when this negative effect is divided absolutely unproportionally between the two variables with the biggest and the smallest impact.

Income is the weakest indicator involved in the model. Each increment of its value by one currency unit - in this case euro

Table 2. Regression models

\begin{tabular}{|l|c|c|c|c|c|c|}
\hline \multirow{2}{*}{ Indicator } & \multicolumn{3}{|c|}{ M1 } & \multicolumn{2}{c|}{ M2 } \\
\cline { 2 - 7 } & $\begin{array}{c}\text { Estimated } \\
\text { coefficient }\end{array}$ & p-value & $\begin{array}{c}\text { Significance } \\
\text { level }\end{array}$ & $\begin{array}{c}\text { Estimated } \\
\text { coefficient }\end{array}$ & $\begin{array}{c}\text { S-value } \\
\text { level }\end{array}$ \\
\hline Unemployment rate & -4.75 & 0.470 & & & & \\
\hline $\begin{array}{l}\text { Mean equivalised net income } \\
\text { per household }\end{array}$ & -0.26 & 0.052 & & -0.33 & $<0.001$ & $*$ * \\
\hline At-risk-of-poverty & 15.46 & 0.017 & $*$ & 11.69 & 0.054 & $*$ \\
\hline Gini coefficient & 150.69 & $<0.001$ & $* * *$ & 148.19 & $<0.001$ & $*$ * \\
\hline Income quintile ratio & -712.61 & $<0.001$ & $* * *$ & -694.75 & $<0.001$ & $* *$ \\
\hline Social benefits & -21.29 & 0.025 & $*$ & 22.36 & 0.005 & $* *$ \\
\hline
\end{tabular}

${ }^{* * *}$ denotes a significance level lower than $0.001,{ }^{* *}$ denotes a significance level lower than 0.01 , but higher than $0.001,{ }^{*}$ denotes a significance level lower than 0.05 , but higher than 0.01 
Table 3. Correlation matrix of explaining variables

\begin{tabular}{|l|c|c|c|c|c|c|}
\hline & $\begin{array}{c}\text { Unemployment } \\
\text { rate }\end{array}$ & $\begin{array}{c}\text { Mean equivalised } \\
\text { net income per } \\
\text { household }\end{array}$ & At-risk-of-poverty & Gini coefficient & $\begin{array}{c}\text { Income quintile } \\
\text { ratio }\end{array}$ & Social benefits \\
\hline Unemployment rate & 1 & -0.1166 & 0.7771 & -0.2015 & -0.0852 & 0.8763 \\
\hline $\begin{array}{l}\text { Mean equivalised } \\
\text { net income per } \\
\text { household }\end{array}$ & -0.1166 & 1 & -0.3542 & 0.1891 & 0.1918 & -0.3948 \\
\hline At-risk-of-poverty & 0.7771 & -0.3542 & 1 & -0.0654 & 0.0726 & 0.7329 \\
\hline Gini coefficient & -0.2015 & 0.1891 & -0.0654 & 1 & 0.9756 & -0.1744 \\
\hline Income quintile ratio & -0.0852 & 0.1918 & 0.0726 & 0.9756 & 1 & -0.0816 \\
\hline Social benefits & 0.8763 & 0.7329 & 0.7329 & -0.1744 & -0.0816 & 1 \\
\hline
\end{tabular}

- brings a decrease of the standardised mortality rate at level of 0.33 .

Poverty brings an increase of the standardised mortality rate. An additional one percentage point means a rise of the standardised mortality rate by 11.69 deaths.

Gini coefficient performs as the second variable, as it has the biggest impact on the standardised mortality rate. Decrease at level of 148.19 deaths is brought by an addition of one percentage point to its value.

Income quintile ratio is the most influential indicator. Its increment by one unit decreases standardised mortality rate by 694.75 deaths. Such a high multiplier is caused by construction of this indicator.

Social benefits behave as the biggest unfavourably influencing variable. Each time a share of population receiving social benefits is increased by one percentage point, the standardised mortality rate is enlarged by 22.36 deaths.

There are several correlated pairs of variables in the model as seen in Table 3. The highest level of correlation lies between the GC and IQR variables. This is based on the fact of their calculation. Very high correlation is between the UR and SB variables. This creates an unusual example, because social benefit as benefit donated to people without any opposite obligation is aimed just right at the unemployed inhabitants, who stand behind the unemployment rate calculation. High correlation is also between the UR and P variables and between the $\mathrm{P}$ and SB variables too. The first couple is understandable from a point of view of the composition and attributes of the inhabitants fulfilling the requirements of poverty. Many people, who live under the threshold of poverty, or de facto all these people are unemployed. Only special cases, which are not covered by the legal norms, are located outside of this state - for instance voluntarily unemployed person under the threshold of poverty. Correlation of the second pair is comprehensible from a point of view of the previous lines. Because the UR and SB variables are correlated and the $\mathrm{P}$ and SB variables are correlated too, there is a presumption for correlation between the UR and P variables, which is confirmed by its value. Another time, the unemployed inhabitants obviously receive unemployment benefits and the poor people in the terms of poverty receive social assistance benefits in order to mitigate their inappropriate financial situation. The other couples of the involved variables are uncorrelated or there is only moderate correlation as it is in a case of the I and P variables and the I and SB variables.
The test statistics of the Breusch-Pagan test reaches a value of 7.9045 on 5 degrees of freedom. A p-value at a level of 0.1616 means no rejection of the zero hypothesis demonstrating a state when the data is characterised by homogeneity. The GoldfeldQuandt test confirms this result. Its test statistics has a value of 1.8406 on 30 degrees of freedom with the p-value at a level of 0.05 exactly. Although it is a boundary value, it is possible to confirm the result of the previous Breusch-Pagan test by no rejection of the zero hypothesis, which is the same.

\section{DISCUSSION}

Expected relationships between the standardised mortality rate and the particular indicators are confirmed with an exception of income quintile ratio. It is disputable whether this is caused by its quantitative construction or by other reason. The Bratislava region seems to bear the most appropriate figures of the mortality rate for the non-communicable diseases. Undoubtly, it is secured by high level of the observed socio-economic indicators. This fact is not sufficiently emphasised in the current policies relating to the public sector. On the other hand, it is not very clear that the opposite side of these results is borne by the regions with the lowest values.

\section{CONCLUSIONS}

Mortality is a reliable picture of public health and it is also the most objective way of measuring health. Development of mortality should be examined in the terms of the regional disparities reflecting the strongly determined factors (20). Just right the differentiation of the country from an angle of view of the regions should be implemented in the regional policies related to the public sector. The outcome of this study and the similar analyses could help to make the regional policies more efficient as the particular region has its own particular needs. The associations solely between income inequality and mortality within the countries are less remembered in the studies. However, it is very important to know the extent to which income or poverty affects the mortality. In the process of the demographic ageing, responsibility for health gets a priority position. By the vigorous prevention programmes targeted to the selected population groups, mortality and morbidity can be actively managed. 


\section{Acknowledgements}

This work is created within the project supported by the Scientific Grant Agency of the Ministry of Education, Science, Research and Sport of the Slovak Republic and the Slovak Academy of Sciences 1/0945/17 Economic research on quantification of marketing processes aimed at improving value for patient, multidimensional analyses of the marketing mix of healthcare facilities and quantification of their importance in the process of establishment of the system to measure the quality and efficiency in healthcare of the Slovak Republic.

\section{Conflict of Interests}

None declared

\section{REFERENCES}

1. Pol L, Thomas R. The Demography of health and healthcare. Dordrecht: Springer; 2013.

2. Bassuk SS, Berkman LF, Amick BC. Socioeconomic status and mortality among the elderly: findings from four US communities. Am J Epidemiol. 2002;155(6):520-33.

3. Stringhini S, Berkman L, Dugravot A, Ferrie JE, Marmot M, Kivimaki M, et al. Socioeconomic status, structural and functional measures of social support, and mortality: the British Whitehall II Cohort Study, 1985-2009. Am J Epidemiol. 2012;175(12):1275-83.

4. Regidor E, Vallejo F, Reques L, Cea L, Miqueleiz E, Barrio G. Area-level socioeconomic context, total mortality and cause-specific mortality in Spain: heterogeneous findings depending on the level of geographic aggregation. Soc Sci Med. 2015;141:142-50.

5. Mackenbach JP, Stirbu I, Roskam AR, Schaap MM, Menvielle G, Leinsalu $\mathrm{M}$, et al. Socioeconomic inequalities in health in 22 European countries. N Engl J Med. 2008;358(23):2468-81.

6. Blakely $\mathrm{T}$, Tobias $\mathrm{M}$, Atkinson J. Inequalities in mortality during and after restructuring of the New Zealand economy: repeated cohort studies. BMJ. 2008;336(7640):371-5
7. World Health Organization. Global status report on noncommunicable diseases 2014. Geneva: WHO; 2014.

8. World Health Organization. Noncommunicable diseases progress monitor 2015. Geneva: WHO; 2015.

9. Di Cesare M, Khang Y, Asaria P, Blakely T, Cowan MJ, Farzadfar F, et al. Inequalities in noncommunicable diseases and effective responses. Lancet. 2013;381(9866):585-97.

10. World Health Organization. Noncommunicable diseases country profiles 2011. Geneva: WHO; 2011.

11. Alwan A, MacLean DR, Riley LM, d'Espaignet ET, Mathers CD, Stevens GA, et al. Monitoring and surveillance of chronic noncommunicable diseases: progress and capacity in high-burden countries. Lancet. 2010;376(9755):1861-8.

12. Kawachi I, Kennedy BP, Lochner K, Prothrow-Stith D. Social capital, income inequality, and mortality. Am J Public Health. 1997;87(9):1491-8.

13. Wilkinson RG. Income distribution and life expectancy. BMJ. 1992;304(6820):165-8.

14. Muller A. Education, income, inequality, and mortality: a multiple regression analysis. BMJ. 2002 Jan 5;324(7328):23-5.

15. Kennedy BP, Kawachi I, Prothrow-Stith D. Income distribution and mortality: cross-sectional ecological study of the Robin Hood index in the United States. BMJ. 1996 Apr 20;312(7037):1004-7.

16. Kaplan GA, Pamuk ER, Lynch JW, Cohen RD, Balfour JL. Inequality in income and mortality in the United States: analysis of mortality and potential pathways. BMJ. 1996 Apr 20;312(7037):999-1003.

17. Kawachi I, Kennedy BP. The relationship of income inequality to mortality: does the choice of indicator mater? Soc Sci Med. 1997;45(7):1121-7.

18. Kibele EUB. Regional mortality differences in Germany. Dordrecht: Springer Science+Business Media Dordrecht; 2012.

19. Kunst AE. Cross-national comparisons of socio-economic differences in mortality. Rotterdam: Erasmus University Rotterdam; 1997.

20. Gavurová B, Vagašová T. Regional differences of standardised mortality rates for ischemic heart diseases in the Slovak Republic for the period 1996-2013 in the context of income inequality. Health Econ Rev. 2016;6:21. doi:10.1186/s13561-016-0099-1.

Received October 17, 2016 Accepted in revised form December 19, 2017 